\title{
Optical microscopy reveals the dynamic nature of $B$. pseudomallei morphology during $\beta$-lactam antimicrobial susceptibility testing
}

Heather P. McLaughlin * (D), Julia Bugrysheva and David Sue

\begin{abstract}
Background: In Gram-negative species, $\beta$-lactam antibiotics target penicillin binding proteins (PBPs) resulting in morphological alterations of bacterial cells. Observations of antibiotic-induced cell morphology changes can rapidly and accurately differentiate drug susceptible from resistant bacterial strains; however, resistant cells do not always remain unchanged. Burkholderia pseudomallei is a Gram-negative, biothreat pathogen and the causative agent of melioidosis, an often fatal infectious disease for humans.

Results: Here, we identified $\beta$-lactam targets in $B$. pseudomallei by in silico analysis. Ten genes encoding putative PBPs, including PBP-1, PBP-2, PBP-3 and PBP-6, were detected in the genomes of susceptible and resistant strains. Real-time, live-cell imaging of $B$. pseudomallei strains demonstrated dynamic morphological changes in broth containing clinically relevant $\beta$-lactam antibiotics. At sub-inhibitory concentrations of ceftazidime (CAZ), amoxicillinclavulanic acid (AMC), and imipenem (IPM), filamentation, varying in length and proportion, was an initial response of the multidrug-resistant strain Bp1651 in exponential phase. However, a dominant morphotype reemerged during stationary phase that resembled cells unexposed to antibiotics. Similar morphology dynamics were observed for AMC-resistant strains, MSHR1655 and 724644, when exposed to sub-inhibitory concentrations of AMC. For all B. pseudomallei strains evaluated, increased exposure time and exposure to increased concentrations of AMC at and above minimal inhibitory concentrations (MICs) in broth resulted in cell morphology shifts from filaments to spheroplasts and/or cell lysis. B. pseudomallei morphology changes were more consistent in IPM. Spheroplast formation followed by cell lysis was observed for all strains in broth containing IPM at concentrations greater than or equal to MICs, however, the time to cell lysis was variable. B. pseudomallei cell lengths were strain-, drug- and drug concentration-dependent.

(Continued on next page)
\end{abstract}

\footnotetext{
* Correspondence: yfq4@cdc.gov

Laboratory Preparedness and Response Branch, Division of Preparedness and Emerging Infections, National Center for Emerging and Zoonotic Infectious Diseases, Centers for Disease Control and Prevention, 1600 Clifton Road NE, MS: H17-5, Atlanta, GA 30333, USA
}

(C) The Author(s). 2020 Open Access This article is licensed under a Creative Commons Attribution 4.0 International License, which permits use, sharing, adaptation, distribution and reproduction in any medium or format, as long as you give appropriate credit to the original author(s) and the source, provide a link to the Creative Commons licence, and indicate if changes were made. The images or other third party material in this article are included in the article's Creative Commons licence, unless indicated otherwise in a credit line to the material. If material is not included in the article's Creative Commons licence and your intended use is not permitted by statutory regulation or exceeds the permitted use, you will need to obtain permission directly from the copyright holder. To view a copy of this licence, visit http://creativecommons.org/licenses/by/4.0/ The Creative Commons Public Domain Dedication waiver (http://creativecommons.org/publicdomain/zero/1.0/) applies to the data made available in this article, unless otherwise stated in a credit line to the data. 
(Continued from previous page)

Conclusions: Both resistant and susceptible B. pseudomallei strains exhibited filamentation during early exposure to AMC and CAZ at concentrations used to interpret susceptibility (based on CLSI guidelines). While developing a rapid $\beta$-lactam antimicrobial susceptibility test based on cell-shape alone requires more extensive analyses, optical microscopy detected B. pseudomallei growth attributes that lend insight into antibiotic response and antibacterial mechanisms of action.

Keywords: Cell morphology, B. pseudomallei, $\beta$-lactam antibiotics

\section{Background}

The World Health Organization (WHO) identified antimicrobial resistance as one of the most important problems for human health that threatens the effective prevention and treatment of infectious diseases [1]. A 2019 Centers for Disease Control and Prevention (CDC) report on antibiotic resistance threats highlights the latest burden estimates for human health in the U.S., listing 18 resistant pathogens into one of three categories: urgent, serious and concerning [2]. Timely administration of appropriate drug therapy is essential for both patient outcomes and for combatting the spread of antibiotic resistance $[3,4]$. $\beta$-lactams are the most common treatment for bacterial infections and the class accounts for $70 \%$ of antibiotic prescriptions in the United States [5]. However, increased exposure of bacteria to a multitude of $\beta$-lactams drives adaptation and has led to the production and mutation of $\beta$-lactamases, resulting in resistance [6].

Melioidosis is a life-threatening human infection with case fatality rates that may exceed $70 \%$ as a result of ineffective antimicrobial therapy [7-9]. Naturally-acquired melioidosis infections are caused by inhalation, ingestion or exposure of broken skin to the pathogen Burkholderia pseudomallei. This disease is endemic across tropical areas and is estimated to account for $\sim 165,000$ human cases per year worldwide, $\sim 89,000$ of which result in death [8]. The United States Federal Select Agent Program includes B. pseudomallei as a Tier 1 biological select agent. Public health and safety could be compromised if this pathogen was deliberately misused due to ease of propagation, small infectious dose, and high mortality rate. Awareness of melioidosis and research into B. pseudomallei is increasing due to the heavy disease burden and the biothreat potential [10].

$\beta$-lactams ceftazidime (CAZ), amoxicillin-clavulanic acid (AMC), and imipenem (IPM) are antibiotics used for melioidosis treatment [9]; however, treatment failures have been attributed to acquired and intrinsic B. pseudomallei drug resistance [11-13]. Drug inactivation and drug target modification are described as mechanisms of resistance. Mutations resulting in amino acid changes in and upstream of the $\beta$-lactamase gene penA confer resistance to AMC, CAZ and IPM in strain Bp1651 and to AMC in strain MSHR1655 [14-16]. In addition, a reversible gene duplication and amplification event in a chromosomal region containing penA resulted in acquired CAZ resistance [17]. Loss of the drug target penicillin-binding protein 3 (PBP-3) also contributes to CAZ-resistance in B. pseudomallei [18].

Inactivation of specific PBPs targeted by $\beta$-lactam antibiotics induces well-defined morphological changes in other Gram negative bacteria: (i) inhibition of PBP-3 leads to formation of filaments, (ii) inhibition of PBP-2 results in the production of round cells and cell-wall deficient spheroplasts, and (iii) inhibition of PBP-1A and PBP-1B induces rapid cell lysis [19]. To date, three PBP3 homologs have been reported in B. pseudomallei [18], but genes encoding putative PBP-2 and PBP-1 have not been identified. Cell morphology can manifest differently when $\beta$-lactams demonstrate an affinity for multiple PBP targets. Moreover, morphological response is dependent on the number of target PBPs present, the antibiotic concentration, and the specificities of enzyme binding sites [19]. Documenting $\beta$-lactam-induced morphology changes could improve our understanding of antibiotic response and mechanisms of action as well as help identify trends that are predictive of $B$. pseudomallei susceptibility.

Early administration of effective drug therapy is critical for positive melioidosis patient outcomes. Rapid phenotypic $\beta$-lactam antimicrobial susceptibility testing (AST) of B. pseudomallei can facilitate the administration of antibiotics with confirmed activity against infecting strains. Optical screening was previously used for the rapid AST of Gram negative biothreat agents to several classes of antibiotics including aminoglycosides, tetracyclines, fluoroquinolones and $\beta$-lactams [20]. The time required to accurately determine susceptibility decreased by up to $70 \%$ compared to conventional broth microdilution (BMD) testing, but most of the antibiotic agents tested did not induce cell filamentation. Microbial growth was measured by estimating bacterial cell surface area and the automated assay could not differentiate between cell elongation and cell division of $\beta$-lactam-induced filamentous cells, including some B. pseudomallei strains grown in 
the presence of CAZ [20]. However, real-time video imaging by microscopy revealed antibiotic-induced cell morphology changes.

Assessment of cell morphology, rather than bacterial density, was previously used to rapidly differentiate susceptible and resistant Gram negative bacteria in the presence of $\beta$-lactams [21-23] and rapid AST based on these analyses showed high categorical agreement compared to gold standard BMD results. The morphological response of resistant strains was variable between studies; some reported that cell shape remained unchanged in the presence of $\beta$-lactams, while others observed cell swelling and filament formation. Here, we use optical microscopy to (i) study morphological responses of drug resistant and susceptible $B$. pseudomallei strains in broth containing $\beta$-lactams, (ii) quantify cell length, shape, and response during exposure to $\beta$-lactams, and (iii) investigate the usefulness of cell morphology for rapid susceptibility testing of $B$. pseudomallei to $\beta$-lactams. We describe the utility of optical screening to explore trends in morphology and capture growth characteristics that may be be indicative of specific antimicrobial response. To achieve this, real-time, live-cell images of B. pseudomallei strains in the presence and absence of CAZ, AMC, and IPM below, at and above MICs were captured and analyzed. We also identify PBP homologs encoded in the B. pseudomallei genome which may represent the potential targets for $\beta$-lactams antibiotics and better explicate the antibacterial mechanisms of action.

\section{Results}

$\beta$-lactam-induced cell morphology dynamics of the multidrug-resistant strain Bp1651

B. pseudomallei strain Bp1651 is resistant to AMC, CAZ, and IPM based on CLSI MIC interpretive criteria (Table 1). Growth in broth culture of this MDR strain was monitored in real-time by optical screening in the presence of each $\beta$-lactam and in CAMHB only. AMC, CAZ, and IPM concentrations tested included the CLSI breakpoint for susceptibility and the three successive two-fold higher concentrations. Optical screening images captured Bp1651 cell morphology during exponential and stationary phase growth (Fig. 1a). In media without antibiotics, cells of typical B. pseudomallei length $(\leq 5 \mu \mathrm{m})$ were observed for Bp1651 throughout all phases of growth. In sub-inhibitory concentrations of AMC, CAZ and IPM, filamentation was detected during exponential phase (Fig. 1a).

As outlined by CLSI, drug resistance or susceptibility of B. pseudomallei by BMD testing is assessed by observations of growth or inhibition of growth at the two-fold concentrations above and below 16/8 $\mu \mathrm{g} / \mathrm{ml} \mathrm{AMC,} 8 \mu \mathrm{g} /$ $\mathrm{ml}$ IPM and $16 \mu \mathrm{g} / \mathrm{ml} \mathrm{CAZ}$. Morphology described at these intermediate drug concentrations act as a reference point for comparison as growth in higher concentrations define resistance for this strain. At intermediate concentrations, the lengths of $100 \mathrm{Bp} 1651$ cells were each measured after $4 \mathrm{~h}$ using the 'thinned length' object feature of the UniExplorer Software. Approximately 20\% of cells exhibited filamentation (lengths $\geq 15 \mu \mathrm{m}$ ) in the presence of $16 / 8 \mu \mathrm{g} / \mathrm{ml}$ AMC (1/4 MIC). More than half of cells $(62 / 100)$ remained $\leq 5 \mu \mathrm{m}$, similar to cells measured in broth alone. The longest cell recorded at this concentration was $29 \mu \mathrm{m}$ (data not shown). After $4 \mathrm{~h}$ at $8 \mu \mathrm{g} / \mathrm{ml} \mathrm{IPM} \mathrm{(1/4} \mathrm{MIC)} \mathrm{and} 16 \mu \mathrm{g} / \mathrm{ml} \mathrm{CAZ} \mathrm{(at} \mathrm{least} 1 / 8$ MIC), some filamentous cells were observed with the longest cells measured at $37 \mu \mathrm{m}$ and $46 \mu \mathrm{m}$, respectively. About half of Bp1651 cells remained $\leq 5 \mu \mathrm{m}$ at these concentrations of IPM (56/100 cells) and CAZ (47/100 cells). Bp1651 formed fewer filaments in higher concentrations of $\operatorname{AMC}(32 / 16 \mu \mathrm{g} / \mathrm{ml})$ and IPM $(16 \mu \mathrm{g} / \mathrm{ml})$ corresponding to $1 / 2$ MIC (Tables 2 and 3). Upon reaching stationary phase growth in the presence of sub-inhibitory concentrations of antibiotics, $\beta$-lactam-induced cell filaments were no longer visible and morphology resembling cells unexposed to antibiotics was restored (Fig. 1a). Video imaging of Bp1651 grown in IPM below the MIC captures the dynamic nature of cell morphology over time (Video 1). In addition, the higher the drug concentration the longer cells remained elongated.

Visual observation of Bp1651 growing in the presence of sub-inhibitory concentrations of CAZ revealed

Table 1 B. pseudomallei strains used in this study

\begin{tabular}{|c|c|c|c|c|}
\hline B. pseudomallei & Antimicrobial Susceptibility Profile & Origin & Country & Year \\
\hline Bp1651 & $A M C^{R}, C A Z^{R}, I P M^{R}$ & Human & USA & 2004 \\
\hline MSHR1655 & $A M C^{R}, C A Z^{S}, I P M^{S}$ & Human & Australia & 2003 \\
\hline 724644 & $A M C^{1}, C A Z^{S}, I^{P} M^{S}$ & Human & USA & 2012 \\
\hline $1026 b$ & $A M C^{S}, C A Z^{S}, I P M^{S}$ & Human & Thailand & 1993 \\
\hline 1631 & $A M C^{S}, C A Z^{S}, I P M^{S}$ & Environmental & Australia & $\mathrm{n} / \mathrm{a}$ \\
\hline 6296 & $A M C^{S}, C A Z^{S}, I P M^{S}$ & Human & USA & 2012 \\
\hline 6788 & $A M C^{S}, C A Z^{S}, I P M^{S}$ & $\mathrm{n} / \mathrm{a}$ & $\mathrm{n} / \mathrm{a}$ & $\mathrm{n} / \mathrm{a}$ \\
\hline
\end{tabular}

B. pseudomallei strains were classified as resistant (R), intermediate (I), or susceptible (S) based on interpretive criteria outlined by CLSI. Information not available (n/a) 


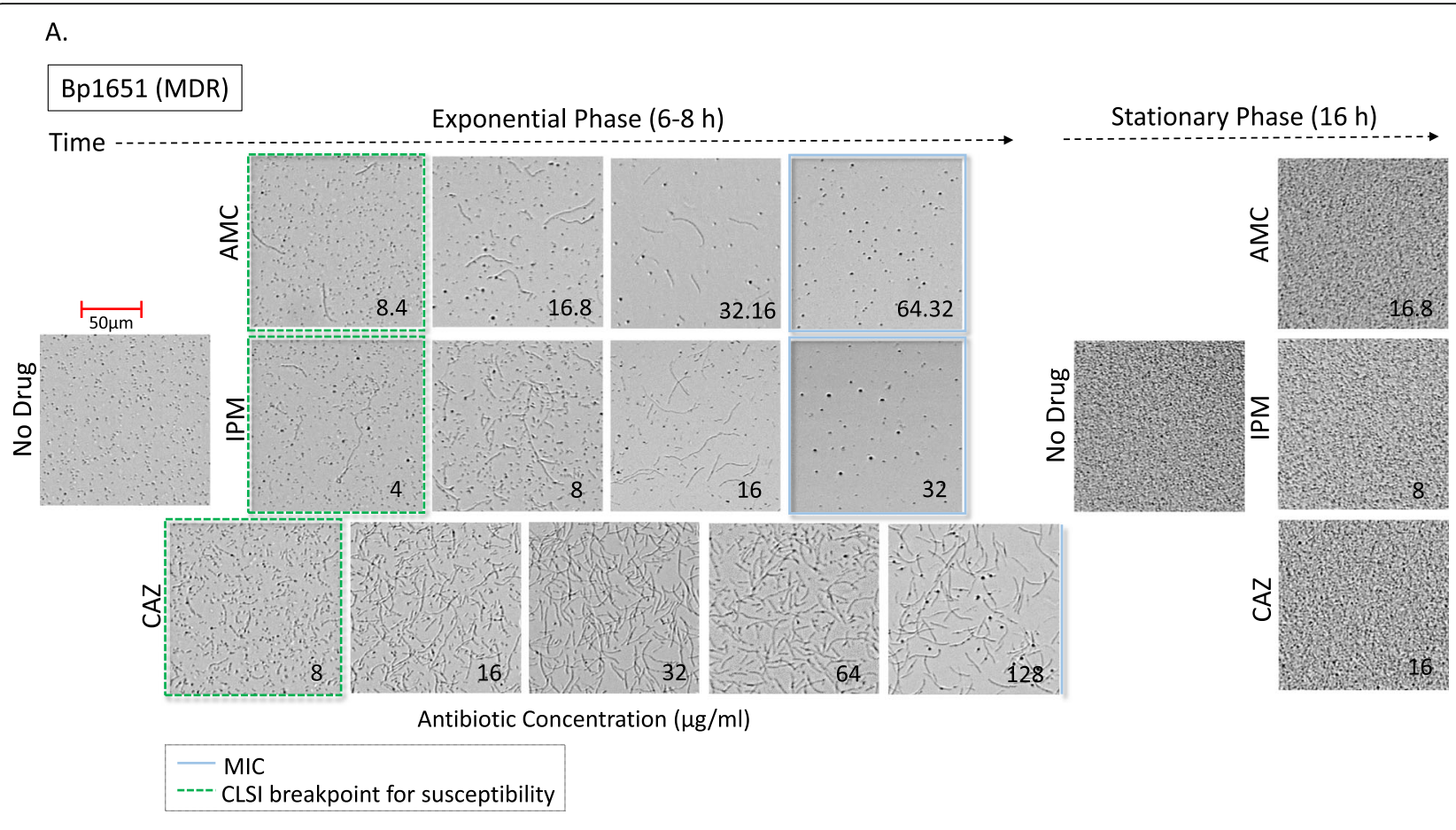

B.
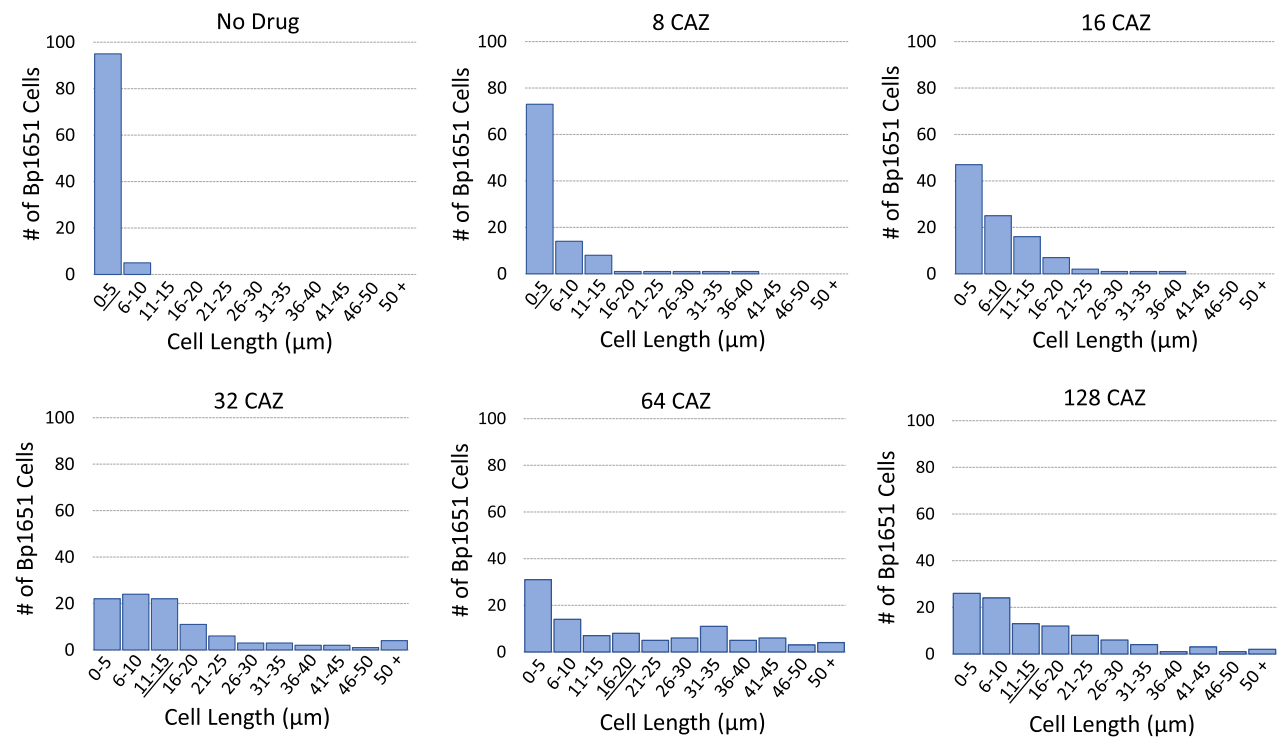

Fig. 1 Cell morphology of the MDR Bp1651 strain cultured in the presence and absence of $\beta$-lactam antibiotics (AMC, CAZ, and IPM) (a). Optical screen images were captured during exponential and stationary phase growth. Drug concentrations $(\mu \mathrm{g} / \mathrm{ml})$ corresponding to the CLSI breakpoint for susceptibility (dotted green squares) and three or four successive two-fold increasing concentrations. Blue squares represent the Bp1651 MICs and the blue line indicates the CAZ MIC is $\geq 128 \mu \mathrm{g} / \mathrm{ml}$. Distribution of cell lengths of Bp1651 cultured in the presence and absence of CAZ $(\mu \mathrm{g} / \mathrm{ml})(\mathbf{b})$. Histograms represent cells $(n=100)$ measured $(\mu \mathrm{m})$ after $4 \mathrm{~h}$ using the thinned length object feature. Multidrug-resistant (MDR), amoxicillin-clavulanic acid (AMC), ceftazidime (CAZ), and imipenem (IPM)

increasing proportions of filamentous cells with increasing drug concentrations up to $64 \mu \mathrm{g} / \mathrm{ml}$. To quantify this direct relationship, the lengths of 100 cells of strain Bp1651 were measured after $4 \mathrm{~h}$ in CAMHB alone and in broth containing two-fold increasing concentrations of CAZ. Histograms depict the distribution of cell lengths (Fig. 1b). In media without drug, $95 \%$ of cells measured $\leq 5 \mu \mathrm{m}$. For cells grown in broth with $8,16,32$, or $64 \mu \mathrm{g} / \mathrm{ml} \mathrm{CAZ,} \mathrm{the} \mathrm{number} \mathrm{of} \mathrm{cells} \mathrm{out} \mathrm{of} 100$ with lengths $\geq 15 \mu \mathrm{m}$ increased from $5,16,36$, and 49 at each 
Table 2 Morphological analysis of B. pseudomallei strains in the presence of AMC and CAZ

\begin{tabular}{|c|c|c|c|c|c|c|c|c|}
\hline \multirow[t]{3}{*}{ Strain } & \multirow{3}{*}{$\begin{array}{l}\text { AMC MIC } \\
(\mu \mathrm{g} / \mathrm{ml})\end{array}$} & \multicolumn{4}{|c|}{ Filamentation (4 h) } & \multicolumn{3}{|c|}{ Time (h) cell lysis begins } \\
\hline & & \multicolumn{2}{|c|}{$1 / 2 \mathrm{MIC}$} & \multicolumn{2}{|l|}{ MIC } & \multirow[t]{2}{*}{$\mathrm{MIC}$} & \multirow[t]{2}{*}{$2 \times \mathrm{MIC}$} & \multirow[t]{2}{*}{$4 \times \mathrm{MIC}$} \\
\hline & & \# Cells $\geq 15 \mu \mathrm{m}$ & Median CL $(\mu \mathrm{m})$ & \# Cells $\geq 15 \mu \mathrm{m}$ & Median CL $(\mu \mathrm{m})$ & & & \\
\hline Bp1651 & 64/32 (R) & $6 / 100$ & 5 & $0 / 100$ & 4 & $3.7 \pm 0.0$ & not tested & not tested \\
\hline MSHR1655 & $32 / 16(R)$ & $62 / 100$ & 19.5 & $61 / 100$ & 19 & $6.1 \pm 0.2$ & $4.0 \pm 0.3$ & not tested \\
\hline 724644 & 16/8 (I) & $93 / 100$ & 59 & $24 / 100$ & 6 & $4.8 \pm 1.0$ & $2.9 \pm 0.2$ & $2.9 \pm 0.2$ \\
\hline 6788 & $\underline{8 / 4}(\mathrm{~S})$ & $86 / 97$ & 43 & $82 / 100$ & 42.5 & $\begin{array}{l}\text { remains } \\
\text { filamentous }\end{array}$ & $\begin{array}{l}\text { filaments and } \\
\text { spheroplasts }\end{array}$ & $\begin{array}{l}\text { only } \\
\text { spheroplasts }\end{array}$ \\
\hline $1026 \mathrm{~b}$ & 4/2 (S) & $42 / 100$ & 12 & $80 / 97$ & 44 & $\begin{array}{l}\text { remains } \\
\text { filamentous }\end{array}$ & remains filamentous & $5.2 \pm 0.4$ \\
\hline \multirow[t]{3}{*}{ Strain } & CAZ MIC & \multicolumn{2}{|c|}{ Filamentation (4 h) } & & & \multicolumn{2}{|c|}{ Time (h) cell lysis begins } & \\
\hline & & \multicolumn{2}{|l|}{$1 / 2 \mathrm{MIC}$} & MIC & & \multirow[t]{2}{*}{ MIC } & \multirow[t]{2}{*}{$2 \times \mathrm{MIC}$} & \multirow[t]{2}{*}{ 4x MIC } \\
\hline & & \# Cells $\geq 15 \mu \mathrm{m}$ & Median CL $(\mu \mathrm{m})$ & \# Cells $\geq 15 \mu \mathrm{m}$ & Median CL ( $\mu \mathrm{m})$ & & & \\
\hline Bp1651 & $>128(\mathrm{R})$ & $49 / 100^{*}$ & $14^{*}$ & $39 / 100^{*}$ & $10.5^{*}$ & $\begin{array}{l}\text { filaments and } \\
\text { spheroplasts }\end{array}$ & not tested & not tested \\
\hline 724644 & $\underline{8}(S)$ & $93 / 100$ & 56.5 & $95 / 100$ & 59.5 & remains filamentous & $\begin{array}{l}\text { remains } \\
\text { filamentous }\end{array}$ & $\begin{array}{l}\text { remains } \\
\text { filamentous }\end{array}$ \\
\hline MSHR1655 & $4(S)$ & $48 / 100$ & 13 & $61 / 100$ & 22 & $8.2 \pm 0.4$ & $8.0 \pm 0.0$ & $8.0 \pm 0.3$ \\
\hline $1026 b$ & $2(S)$ & $28 / 100$ & 8 & $94 / 100$ & 36 & remains filamentous & remains filamentous & $\begin{array}{l}\text { remains } \\
\text { filamentous }\end{array}$ \\
\hline
\end{tabular}

The minimal inhibitory concentrations (MICs) of amoxicillin-clavulanic acid (AMC) and ceftazidime (CAZ) were determined by conventional BMD testing based on CLSI guidelines. Susceptibility interpretations are defined as resistant (R), intermediate (I), or susceptible (S). Cell length (CL) was measured at time $4 \mathrm{~h}$ and median cell length at MICs was calculated ( $\mathrm{n}=95$ to 100 cells). Time to cell lysis is represented as the mean \pm SD of triplicate samples based on growth kinetic data and visual observation of video imaging. $\left(^{*}\right)$ filamentation and cell lysis data in the presence of CAZ was calculated using a value of $128 \mu \mathrm{g} / \mathrm{ml}$ for the MIC due to concentration range in drug panel for testing. Underlined drug concentration indicates breakpoint for susceptibility

two-fold increasing concentration. The proportion of Bp1651 cells measuring $\leq 5 \mu \mathrm{m}$ decreased substantially in

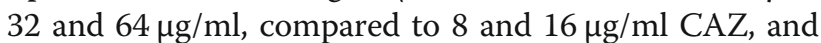
cells reaching lengths of $>50 \mu \mathrm{m}$ were observed at these concentrations (Fig. 1b). The median cell lengths for Bp1651 grown in CAMHB alone, and in broth containing $8,16,32,64$, and $128 \mu \mathrm{g} / \mathrm{ml} \mathrm{CAZ} \mathrm{were} 3,4$, $6,11.5,14$ and $10.5 \mu \mathrm{m}$, respectively (Fig. $1 \mathrm{~b}$ ). The longest Bp1651 cell length $(73 \mu \mathrm{m})$ was recorded in $64 \mu \mathrm{g} /$ $\mathrm{ml}$ CAZ. More spheroplasts were visible during imaging of exponential phase cells at the highest $(128 \mu \mathrm{g} / \mathrm{ml})$ CAZ concentration tested (Fig. 1a).

Table 3 Morphological analysis of B. pseudomallei strains in the presence of IPM and optical screening-based IPM susceptibility testing

\begin{tabular}{|c|c|c|c|c|c|c|c|}
\hline \multirow[t]{2}{*}{ Strain } & \multirow{2}{*}{$\begin{array}{l}\text { IPM } \\
\text { MIC } \\
(\mu g / \\
m l)\end{array}$} & \multirow{2}{*}{$\begin{array}{l}\text { Filamentation } \\
\text { (\# Cells } \geq 15 \mu \mathrm{m} \text { ) } \\
1 / 2 \mathrm{MIC}\end{array}$} & \multicolumn{2}{|c|}{ Time (h) to determine IPM susceptibility } & \multicolumn{3}{|c|}{ Time (h) cell lysis begins } \\
\hline & & & $4 \mu \mathrm{g} / \mathrm{ml}$ & $8 \mu \mathrm{g} / \mathrm{ml}$ & MIC & $2 \times \mathrm{MIC}$ & $8 \mu \mathrm{g} / \mathrm{ml}$ \\
\hline Bp1651 & $32(\mathrm{R})$ & yes $(8 / 100)$ & ND & ND & $3.6 \pm 0.2$ & not tested & not testec \\
\hline 724644 & $2(S)$ & no & $1.7 \pm 0.0$ & $1.7 \pm 0.0$ & $3.0 \pm 0.0$ & $2.9 \pm 0.2$ & $3.0 \pm 0.0$ \\
\hline MSHR1655 & $1(\mathrm{~S})$ & yes $(15 / 100)$ & $2.0 \pm 0.4$ & $1.3 \pm 0.9$ & $3.9 \pm 0.4$ & $4.0 \pm 0.7$ & $3.6 \pm 0.2$ \\
\hline $1026 b$ & $1(\mathrm{~S})$ & no & $3.5 \pm 0.2$ & $3.8 \pm 0.7$ & $5.0 \pm 0.7$ & $5.3 \pm 0.6$ & $5.7 \pm 0.9$ \\
\hline 1631 & $0.5(S)$ & no & $3.9 \pm 0.2$ & $3.7 \pm 0.5$ & $9.1 \pm 0.5$ & $8.2 \pm 0.8$ & $4.6 \pm 0.2$ \\
\hline 6296 & $0.25(\mathrm{~S})$ & yes $(6 / 100)$ & $2.7 \pm 1.4$ & $3.7 \pm 0.0$ & $9.8 \pm 0.2$ & $8.3 \pm 1.4$ & $5.3 \pm 0.3$ \\
\hline
\end{tabular}

The minimal inhibitory concentrations (MICs) of imipenem (IPM) determined by conventional BMD testing based on CLSI guidelines and the time (h) required to determine susceptibility of $B$. pseudomallei strains $(4 \mu \mathrm{g} / \mathrm{ml}$ and $8 \mu \mathrm{g} / \mathrm{ml}$ IPM) by optical screening with a confidence level (CL) of $95 \%(p \leq 0.05)$ are listed. Susceptibility interpretations are resistant (R) or susceptible (S). All susceptible strains were monitored by optical screening $18-20 \mathrm{~h}$ in the presence of IPM below, at and above MICs. Cell length was measured after $4 \mathrm{~h}$. Detection of filamentation in sub-inhibitory concentrations and cell lysis at inhibitory concentrations was achieved by analysis of growth kinetic data and visual observation of real-time video imaging. No statistically significant differences were observed between growth values of Bp1651 in the presence $(4 \mu \mathrm{g} / \mathrm{ml}$ and $8 \mu \mathrm{g} / \mathrm{ml})$ and absence of IPM, therefore the time to susceptibility was not determined (ND) 
Growth kinetic graphs of Bp1651 in the presence of AMC and IPM show growth inhibition in CAMHB containing $64 / 32 \mu \mathrm{g} / \mathrm{ml}$ and $32 \mu \mathrm{g} / \mathrm{ml}$, respectively (Fig. S1A \& Fig. S1B). At these MICs, spheroplasts formed during exponential phase (Fig. 1a) and cell lysis began after $3.7 \pm 0.0 \mathrm{~h}$ (AMC) and $3.6 \pm 0.2 \mathrm{~h}$ (IPM) (Tables 2 and 3). There was no evidence of cell filamentation at AMC or IPM MICs and median cell lengths were 4 and $3 \mu \mathrm{m}$, respectively.

\section{Cell morphology dynamics during B. pseudomallei $\beta$ - lactam AST}

Based on CLSI interpretative criteria for BMD testing for AMC, strain MSHR1655 is categorized as resistant (MIC of $32 / 16 \mu \mathrm{g} / \mathrm{ml}$ ), 724644 is intermediate (MIC of $16 / 8 \mu \mathrm{g} / \mathrm{ml})$, Bp6788 is susceptible with an MIC at the breakpoint $(8 / 4 \mu \mathrm{g} / \mathrm{ml})$ and $1026 \mathrm{~b}$ is susceptible (MIC of $4 / 2 \mu \mathrm{g} / \mathrm{ml}$ ). All B. pseudomallei study strains, except Bp1651, are CAZ-S and IPM-S based on conventional BMD testing (Tables 1). Optical microscopy was used to generate automated growth kinetic data and to acquire complementary video imaging of cell morphology dynamics of B. pseudomallei strains in the presence of AMC, CAZ, and IPM and in a broth only control (Figs. 2 and 3). Morphology was monitored in antibiotic concentrations less than, equal to, and greater than MICs for each strain, which includes concentrations equivalent to the CLSI susceptibility breakpoints for each drug. All broth cultures were monitored over $18-20 \mathrm{~h}$ and optical screening images were captured during exponential phase growth after $6 \mathrm{~h}$ unless otherwise indicated. Average kinetic graphs $(n=3)$ for each growth condition were overlaid on optical screen images and cell morphology dynamics are described below each image. In media without the addition of antibiotics, there was no evidence of cell elongation for B. pseudomallei, however, variable aggregation was observed between strains (Fig. 2a). Video imaging of strain 724644 showed cells amassing in groups during the first $10 \mathrm{~h}$ of growth in no-drug media (Video 2). Aggregation of cells was not observed for MDR strain Bp1651 or the susceptible Bp6788 in broth media alone (Fig. 1a and Fig. S2).

\section{$A M C$}

At sub-inhibitory concentrations of AMC, some filamentous cells were observed early on for the resistant, intermediate and susceptible $B$. pseudomallei strains (Fig. 2a, Table 2). At $1 / 2$ MIC values, the number of cells $\geq 15 \mu \mathrm{m}$ was variable between strains and ranged from $42 / 100$ (1026b) to 93/100 (724644) (Table 2). The shortest filaments were observed for AMC-resistant strain MSHR1655. Except for Bp6788, during stationary phase growth in AMC concentrations below the MIC, replication of non-elongated cells was seen for the majority of strains. Video footage of strain 724644 grown in media containing AMC equivalent to $1 / 4$ (Video 3) and $1 / 2$ (Video 4) the MICs demonstrates dynamic AMCinduced cell morphology changes over time. In the presence of $4 / 2 \mu \mathrm{g} / \mathrm{ml}$ AMC ( $1 / 4 \mathrm{MIC}$ ), cells were slightly elongated over the first few hours of growth, with replication of cells resembling those not exposed to drug following quickly thereafter. At the CLSI breakpoint for susceptibility of $8 / 4 \mu \mathrm{g} / \mathrm{ml} \mathrm{AMC} \mathrm{(1/2} \mathrm{MIC),} 724644$ cell filaments are considerably longer, and replication of non-elongated cells is detected much later in stationary phase $(\sim 18 \mathrm{~h})$.

Some evidence of cell filamentation was also observed for all strains during early exponential phase growth in broth with AMC at either the MIC or at $16 / 8 \mu \mathrm{g} / \mathrm{ml}$, a concentration used to interpret $B$. pseudomallei susceptibility by conventional BMD (Fig. 2a \& Fig. S2). Following initial filamentation at MICs, formation of spheroplasts and cell lysis was observed for strains MSHR1655 and 724644 after $6.1 \pm 0.2$ and $4.8 \pm 1.0 \mathrm{~h}$, respectively (Table 2). Growth values initially increased in the growth kinetic graphs, and then subsequently decreased over time. However, detection of spheroplast formation and cell lysis could not be used to predict MICs as 1026b and Bp6788 remained filamentous over time at these AMC levels (Fig. 2a). Due to cell elongation, growth kinetic graphs could not accurately depict susceptibility, as microbial growth is based on changes in the surface area covered by all identified objects in a scan frame. Broth containing $4 \mathrm{x}$ MIC was required to induce cell lysis of $1026 \mathrm{~b}$ which commenced after $5.2 \pm$ $0.4 \mathrm{~h}$. Differences in cell morphology between strains early on at AMC MICs are apparent by the median cell length (MCL) values $(n=97-100)$ calculated after four hours which range from 6 to $44 \mu \mathrm{m}$ (Table 2).

The length of 724644 cells was variable when measured in the presence of AMC below, at and above MICs for this strain. Cells of strain 724644 were measured in media without drug after two hours, without drug after four hours when cells had begun to aggregate, and in two-fold increasing concentrations of AMC after four hours (Fig. 4a). Distribution of cell lengths $(\mu \mathrm{m})$ is depicted and MCLs are indicated by horizontal lines. Consistent with $B$. pseudomallei size, the MCL of strain 724644 grown in broth alone after two hours was $5.71 \mu \mathrm{m}$. Since the thinned length algorithm may not accurately identify overlapping cells as individual cells, the objects measured after four hours are more reflective of groups of aggregated cells, and at this time the MCL was

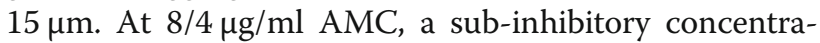
tion, the distribution of filament lengths was wide, with the longest cell reaching $126 \mu \mathrm{m}$ (Fig. 4a). Unlike AMC$\mathrm{R}$ strain Bp1651, in which only spheroplasts were detected at the MIC $(64 / 32 \mu \mathrm{g} / \mathrm{ml})$, both filaments and 
A.
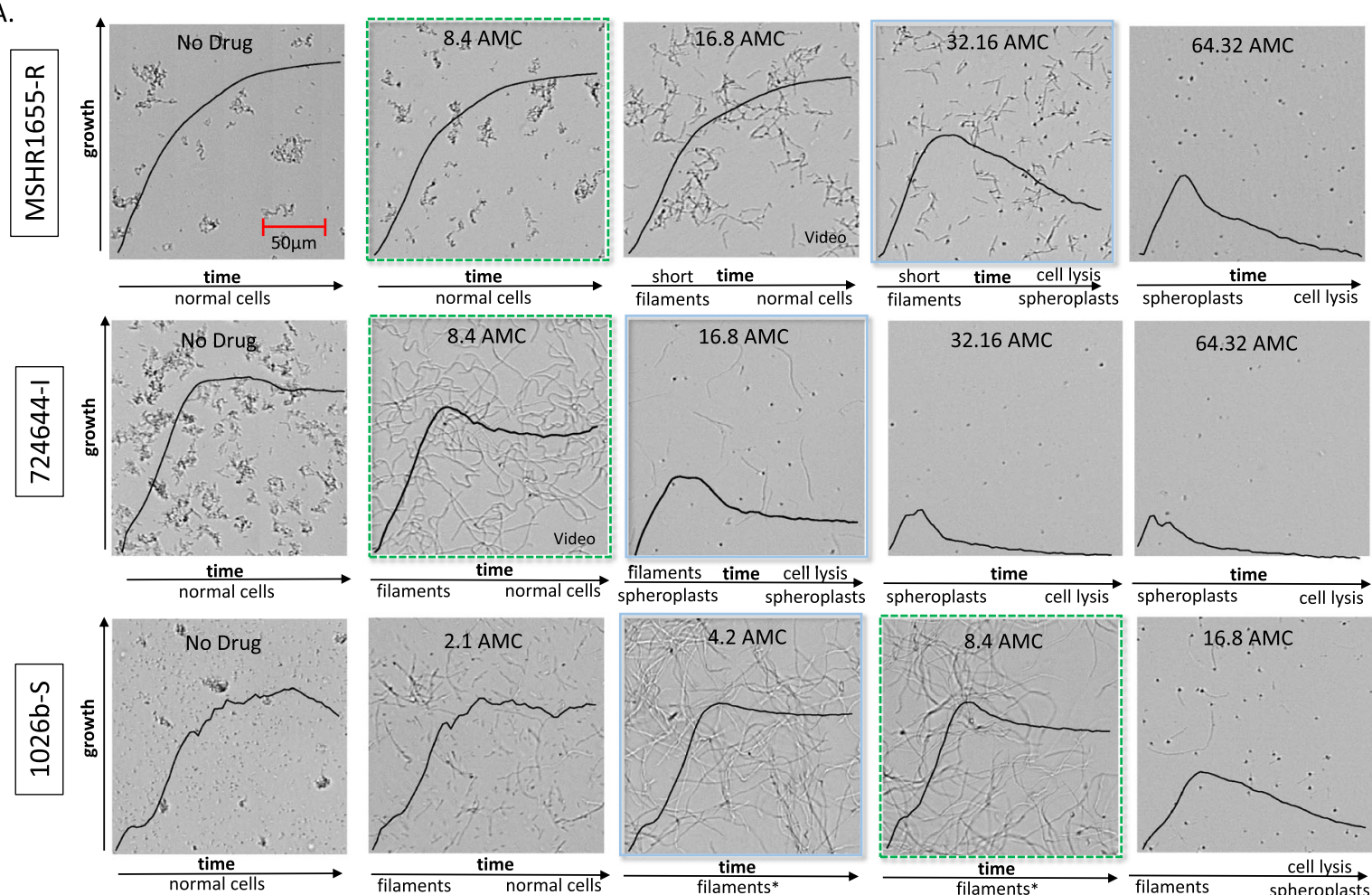

B.
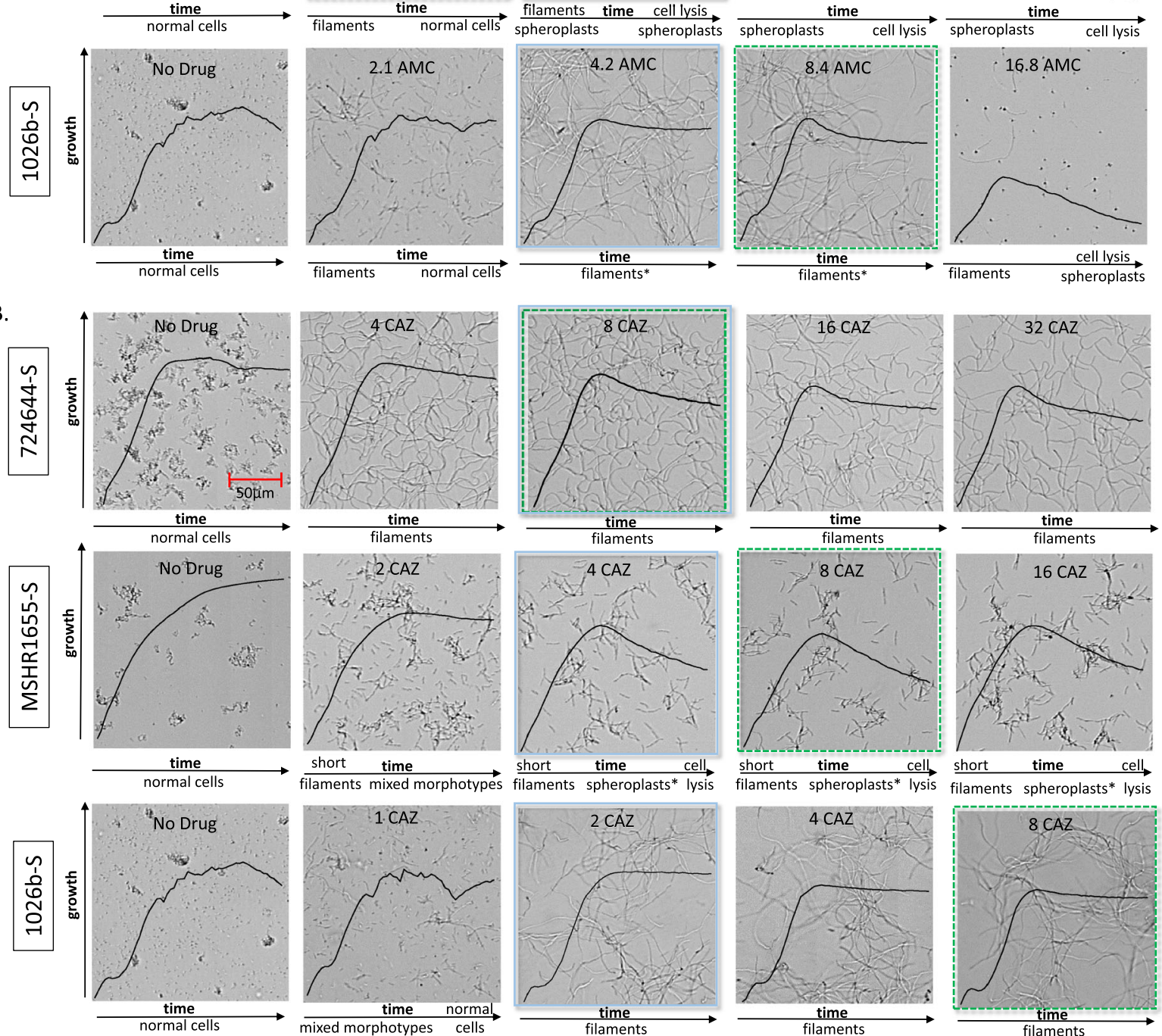

Fig. 2 Cell morphology of B. pseudomallei strains cultured in the presence and absence of AMC (a) or CAZ (b). Optical screen images were captured after $6 \mathrm{~h}$. Growth kinetic graphs (black lines) represent the average growth value of triplicate samples (y-axis) over time (18 h, $x$-axis) and morphology dynamics are described below each image. Strains are designated as resistant (R), intermediate resistant (I), or susceptible (S) to each antibiotic. Indication that a small proportion of spheroplasts were observed $\left(^{*}\right)$. Drug concentrations $(\mu \mathrm{g} / \mathrm{ml})$ tested were below, equal to, and above MICs (blue squares) for each strain. CLSI breakpoint for susceptibility (dotted green square), amoxicillin-clavulanic acid (AMC), and ceftazidime (CAZ) 


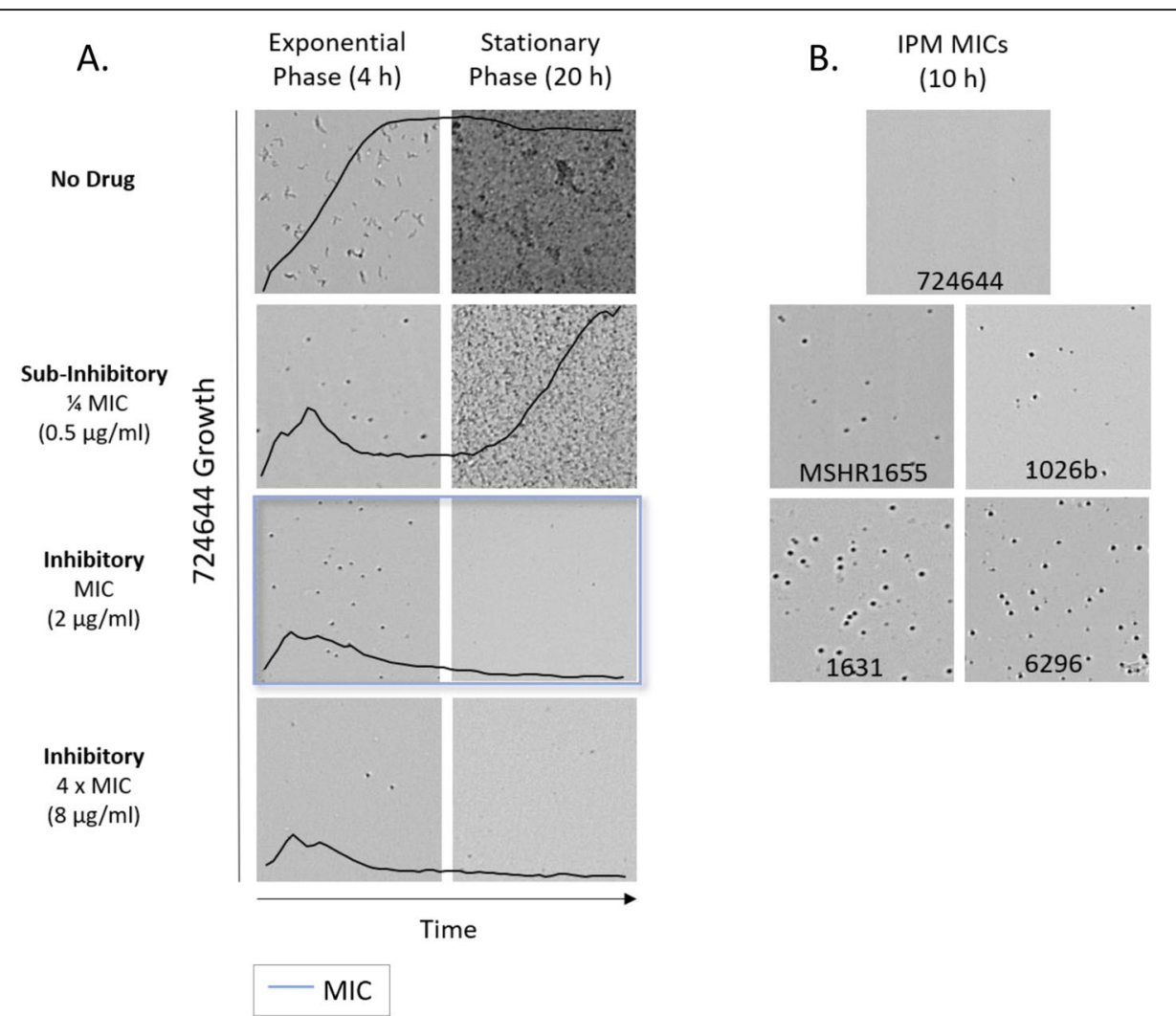

Fig. 3 Cell morphology of B. pseudomallei strains cultured in the presence and absence of IPM. Optical screen images of 724,644 (a) were captured during exponential phase growth $(4 \mathrm{~h})$ or during stationary phase $(20 \mathrm{~h})$. Imipenem (IPM) concentrations tested were below, equal to, and above the MIC (blue square). Growth kinetic graphs represent the average growth value of triplicate samples (y-axis) taken over time (20 h, $x$ axis). Optical screen images of B. pseudomallei strains in the presence of IPM MICs after $10 \mathrm{~h}$ (b)

spheroplasts were observed at the MIC $(16 / 8 \mu \mathrm{g} / \mathrm{ml})$ for AMC-I strain 724644. Morphological heterogeneity of 724644 cells was documented throughout exponential phase prior to cell lysis (Fig. 4b). A heterogenous cell population, made up of both filaments and spheroplasts, was also observed for AMC-S strain Bp6788, but only in broth containing $2 \times \mathrm{MIC}(16 / 8 \mu \mathrm{g} / \mathrm{ml})$ (Fig. S2). While the MCL was $6 \mu \mathrm{m}, 15 / 100$ cells were $\geq 20 \mu \mathrm{m}$. Increasing concentrations of AMC above the MICs induced the formation of more spheroplasts and resulted in quicker cell lysis for $-\mathrm{R},-\mathrm{I}$ and $-\mathrm{S}$ B. pseudomallei strains (Fig. 2a \& Table 2).

\section{$C A Z$}

The CAZ MIC for strain 724644 was equivalent to the CLSI breakpoint for susceptibility $(8 \mu \mathrm{g} / \mathrm{ml})$. This strain formed long filaments in both sub-lethal and lethal concentrations of CAZ through all growth phases (Fig. 2b), with more than $90 \%$ of cells measured $\geq 15 \mu \mathrm{m}$ after four hours (Table 2). Exposure to CAZ over time also induced long filaments for the susceptible 1026b in concentrations greater than or equal to the MIC, but not to the same degree in sub-lethal amounts at $1 / 2$ MIC value
$(1 \mu \mathrm{g} / \mathrm{ml})$ (Fig. 2b). As a result of filamentation, instrument-derived growth values could not be used to accurately determine susceptibility to CAZ. A wide distribution of cell lengths was noted for 724644 after four hours in all concentrations of CAZ tested, with MCLs between 53.5 and $66.5 \mu \mathrm{m}$ (Fig. 4). Cells with lengths $\geq 100 \mu \mathrm{m}$ were also recorded at each concentration. During exponential phase growth, CAZ induced the formation of shorter filaments for the susceptible MSHR1655 strain (Fig. 2b). In the presence of 4 and $8 \mu \mathrm{g} / \mathrm{ml}$ (MIC and $2 \times$ MIC), MCLs were $22 \mu \mathrm{m}$. Unlike 724644, formation of spheroplasts and cell lysis was observed for MSHR1655 exposed to inhibitory CAZ concentrations, however these morphology changes did not occur rapidly. Cell lysis was observed after $\sim 8 \mathrm{~h}$ in concentrations of CAZ corresponding to the 1 to $4 \mathrm{x}$ MIC (Table 2). Video imaging of MSHR1655 showed morphology changes including, formation of short filaments, followed by spheroplasts and subsequent cell lysis in media containing $16 \mu \mathrm{g} / \mathrm{ml} \mathrm{CAZ,} 4 \times$ MIC (Video 5). As growth values for MSHR1655 decreased in later time points due to cell lysis, susceptibility based on optical screening could be determined for this strain (Fig. S1C). At 4 and 


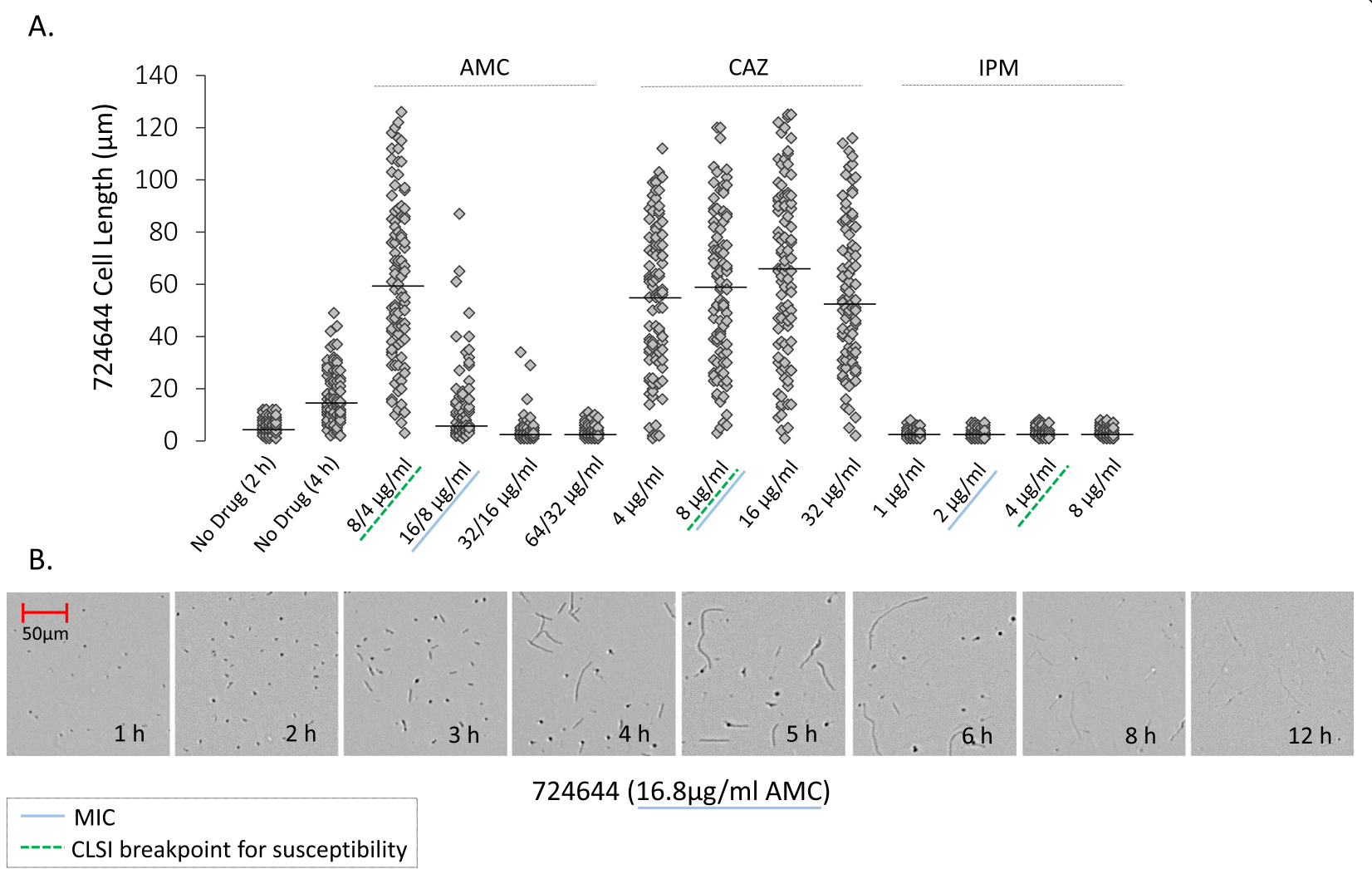

Fig. 4 Cell length and morphology of strain 724,644 cultured in the presence and absence of $\beta$-lactam antibiotics. The dot plot (a) represents the distribution of cell lengths $(n=95-100)$ measured $(\mu \mathrm{m})$ using the thinned length object feature. Cells in media without antibiotics were measured after $2 \mathrm{~h}$ and $4 \mathrm{~h}$ and cell exposed to amoxicillin-clavulanic acid (AMC), ceftazidime (CAZ) and imipenem (IPM) were measured after $4 \mathrm{~h}$. Median cell lengths were calculated (black lines). CLSI breakpoint for susceptibility (green underline) and MICs (blue underline). Optical screen images taken over time (b) in the presence of the MIC value of AMC

$8 \mu \mathrm{g} / \mathrm{ml} \mathrm{CAZ} \mathrm{(1} \mathrm{to} 2 \times \mathrm{MIC}$ ), the latter concentration corresponding to the CLSI breakpoint, susceptibility was determined after $\sim 9 \mathrm{~h}$.

\section{IPM}

Here, we performed rapid, optical screening-based AST and monitored IPM-induced morphology changes for five susceptible B. pseudomallei strains with MICs ranging from 0.25 to $2 \mu \mathrm{g} / \mathrm{ml}$ (Table 3). Unlike AMC and CAZ, cell filamentation was not observed in broth containing IPM at and above the MICs in video imaging of resistant or susceptible strains. Instrument-derived growth values could be used to accurately monitor bacterial replication in IPM. Since growth is inhibited for all susceptible B. pseudomallei strains at $4 \mu \mathrm{g} / \mathrm{ml}$ IPM based on CLSI interpretive criteria for conventional BMD, AST was performed at this concentration and at the intermediate breakpoint concentration of $8 \mu \mathrm{g} / \mathrm{ml}$. Due to the rapid formation of spheroplasts followed by cell lysis induced by IPM for all B. pseudomallei strains tested, the time required to determine susceptibility was between $1.3 \pm 0.9$ and $3.9 \pm 0.2 \mathrm{~h}$ in both concentrations (Table 3). To investigate whether cell lysis observations are useful to rapidly determine the strain MIC, the time in which this event occurred was also recorded for each B. pseudomallei strain. At these concentrations, time to cell lysis was variable between strains commencing as early as $3.0 \pm 0.0$ to $h$ for 724644 and as late as $9.8 \pm 0.2$ h for Bp6296 (Fig. 3a \& Table 3). Optical screening images of strains captured in the presence of MICs of IPM after $10 \mathrm{~h}$ showed more spheroplasts were present for strains with longer times to cell lysis (Bp6296 and Bp1631) (Fig. 3b). At $8 \mu \mathrm{g} / \mathrm{ml}$ IPM (2 to $32 \times$ MIC values), optical screening-based susceptibility could be determined faster for strains 724644 and MSHR1655 that lysed more quickly and the time range for cell lysis was narrower between strains, occurring between $\sim 3.0$ to $6.0 \mathrm{~h}$ (Table 3).

In CAMHB containing IPM equivalent to $1 / 2$ the MIC, cell filamentation was not observed during exponential phase growth for three of five study strains. Though, similar to IPM-R Bp1651, a small proportion of filamentous cells was seen in video footage of IPM-S strains Bp6296 and MSHR1655 during the first several hours. Some strains displayed an extended lag phase in subinhibitory levels of IPM. For instance, at $1 / 4$ MIC of IPM, 
after strain 724644 initially formed spheroplasts and underwent some cell lysis, a prolonged lag phase was observed until cells begin to replicate after 11 to $11.3 \mathrm{~h}$ (Fig. 3a and Video 6). No lag phase was observed for strain 724644 in lower concentrations of IPM, and rapid cell lysis was induced at and about the MIC (Fig. 3a). In media containing $1 / 2$ IPM MIC, both resistant and susceptible strains Bp1651 (Fig. S1B) and Bp1631, respectively, displayed a lag phase lasting $\sim 9 \mathrm{~h}$.

\section{In silico identification of penicillin binding proteins in $B$. pseudomallei}

Ten genes encoding putative PBPs were identified in $B$. pseudomallei $1026 \mathrm{~b}$ using the UniProtKB database. Based on conserved PBP domains predicted by Pfam and homology to PBPs in Pseudomonas aeruginosa PAO1, strain 1026b contains five high molecular mass (HMM), multi-modular (containing both transglycosylase and transpeptidase domains), class-A PBP-1 homologs (II0265, II0898, I3403, I1297, and II2482). Four predicted HMM, class-B homologs containing transpeptidase domains were also identified; one PBP-2 (I3332) and three PBP-3s (I0276, II1292 and II1314) as well as one low MM class-C PBP-6 (I3098) protein which contains a D-alanyl-D-alanine carboxypeptidase domain. NCBI Protein BLAST analyses revealed these B. pseudomallei 1026b PBP homologs share 29.2-45.5\% identity to PBPs in P. aeruginosa PAO1. Ten corresponding PBP homologs were also encoded in the genomes of the resistant strains Bp1651 and MSHR1655 and the susceptible strain Bp6296.

\section{Discussion}

PBPs are the targets for $\beta$-lactam antibiotics and their inactivation results in specific cell morphology changes. Different variables can affect $\beta$-lactam-induced, PBPmediated morphological changes including the $\beta$-lactam, its concentration, the duration of the exposure, the bacterial species, and antimicrobial susceptibility [24-26]. PBP profiles and the binding affinity and kinetic interactions of $\beta$-lactams with PBPs are variable between species [27-29]. Here we identified 10 genes encoding putative PBPs in genomes of both susceptible and resistant $B$. pseudomallei strains, and these may represent the targets for $\beta$-lactams antibiotics. While the binding affinities of $\beta$-lactams for B. pseudomallei PBPs have not been investigated, drug-induced morphological changes can offer insight into bacterial response and antibacterial mechanisms of action.

For B. pseudomallei, cell morphology changes in the presence of AMC was strain dependent and varied based on drug concentration and exposure time. In sub-lethal concentrations of AMC, filament formation in broth was evident for all strains tested at varying lengths and at variable proportions of cell populations. During exponential phase growth at AMC MICs, diverse cell morphologies were observed among strains, including formation of filaments, round spheroplasts, and a heterogenous population of both. Higher concentrations of AMC at and above MIC values resulted in increased proportions of spheroplasts and/or subsequent cell lysis in the study strains, which may indicate inactivation of PBP-2 and PBP-1. In Escherichia coli, the primary affinity of amoxicillin is directed towards these two PBPs [25]. In this study, increased spheroplast formation of $B$. pseudomallei strain 724644 at higher AMC concentrations resulted in shorter cells and more narrow cell length distribution patterns. The concentration of AMC that ultimately led to cell lysis was variable between strains and ranged from one to four times the MIC values for every B. pseudomallei strain evaluated. A change in cell morphology from filaments to spheroplasts or lysis has also been shown to increase with the duration of $\beta$-lactam exposure [30], which we observed herein. Morphological heterogeneity of cell populations was also observed in the presence of AMC for resistant and susceptible strains. These mixed morphologies may indicate that more than one PBP was targeted by AMC.

Cephalosporins such as CAZ have been shown to target PBP-3 and PBP-1 at low and high concentrations, respectively $[25,26,31]$. Both filamentation and subsequent cell lysis of select strains were observed for B. pseudomallei in the presence of CAZ, herein and in previous work [20]. At early time points during incubation in broth with CAZ concentrations below, at and up to eight times the MIC, susceptible B. pseudomallei strains 724644 and MSHR1655 formed long and short filaments, respectively. Based on our observations, CAZ may have a higher selective affinity for PBP-3 in strain 724644 which remained filamentous over time, whereas inhibition of a PBP-1 protein in MSHR1655 could be responsible for cell lysis at later time points. The resistant strain Bp1651 formed filaments early on in subinhibitory levels of CAZ. Then, the original cell size, resembling those cells unexposed to antibiotics, was reestablished at later time points. The time to restoration of this morphology was concentration-dependent and may be a result of CAZ degradation by the $\beta$-lactamase enzyme, PenA [14]. Chen et al [32] demonstrated that filamentation of $B$. pseudomallei in sub-lethal CAZ concentrations could be reversed after antimicrobial removal and that revertant bacteria developed resistance. CAZ PBP-binding specificities, which are reflected by morphology changes, have been previously shown to differ by genus or isolate [24]. Buijs et al. [24] demonstrated Klebsiella spp. formed shorter filaments than $P$. aeruginosa and Acinetobacter spp., and one K. pneumoniae isolate displayed no filamentation in CAZ. 
For both susceptible and resistant B. pseudomallei, bacterial populations treated with CAZ resulted in a wide distribution of cell lengths and were variable between strains. Bp1651 cells were shorter in the lowest and highest filament-inducing, sub-inhibitory CAZ concentrations. These observations are consistent with morphological studies of other Gram-negative species [24]. Median cell length of the susceptible strain 724644 was more independent of CAZ concentration and cells with lengths greater than $100 \mu \mathrm{m}$ were recorded in CAZ and AMC. Filaments with lengths up to $93 \mu \mathrm{m}$ in the presence of sub- and lethal concentrations of $\beta$-lactams have been observed [33].

B. pseudomallei morphological changes with IPM included filamentation, spheroplast formation and lysis. In the presence of IPM at $1 / 2$ the MIC, a small proportion of filamentous cells was observed in the first few hours for the resistant strain Bp1651 and for two of five susceptible B. pseudomallei strains. Exposure to meropenem (MEM) for two hours induced filamentation in carbapenem-resistant $P$. aeruginosa mutants and their susceptible parents at this concentration [34]. At the IPM MIC, B. pseudomallei strains formed spheroplasts at an early growth phase, similar to Acinetobacter baumannii [35]. These B. pseudomallei cells are morphologically typical of spheroplasts, with a nearperfect spherical shapes and found as individuals rather than in cell arrangements like ovoid cells [36]. Future studies may assess the osmotic stability of these B. pseudomallei cells, as spheroplasts are characteristically instable [26, 37]. Satta et al. [38] defined the relationship between cell killing kinetics and PBP binding in E. coli, by demonstrating IPM concentration-dependent PBP inhibition. Saturation of more than one PBP resulted in different rates of cell lysis. Here, at IPM MICs, the exposure time resulting in bacteriolysis was variable among $B$. pseudomallei isolates ( 3 to $10 \mathrm{~h})$. It is plausible that the rate of PBP-1 and PBP-2 saturation is variable between strains and may explain the different times to bacteriolysis.

After spheroplast formation and some cell lysis were observed at $1 / 2$ and $1 / 4$ the IPM MIC for strains Bp1651 and 724644, respectively, morphology and exponential phase growth were restored at later time points. In clinical isolates of Enterobacter cloacae and Klebsiella spp., carbapenem tolerance was mediated by cell wall-deficient spheroplasts [39]. It is suggested that Gram-negative pathogens have the ability to survive for extended periods without structurally sound cell walls and that morphological recovery and cell division are possible upon removal of antimicrobials [39]. $\beta$-lactam-treated isolates from patients were shown to contain spheroplasts, which may contribute to the high tolerance observed for some clinical isolates [39-41]. Recurrence of B. pseudomallei infection is one of the most relevant complications in melioidosis survivors and treatment and prophylaxis must be tailored to individual patients according to clinical manifestations and response [42, 43]. Investigations studying the survival of $B$. pseudomallei spheroplasts exposed to and then removed from the presence of IPM/MEM in vitro and in vivo may inform therapeutic decision making, especially if carbapenem levels drop or if antibiotic administration is discontinued.

Novel approaches, including high-powered optical microscopy, microfluidic assays, flow cytometry, and dielectrophoresis systems, allow for cellular-level observation of bacterial morphologies [20, 21, 23, 44]. These analyses have been used to develop rapid antimicrobial susceptibility tests for several Gram-negative organisms. $\mathrm{Su}$ et al. [23] used a dielectrophoretic system to accurately and rapidly determine susceptibility of several Gram-negative spp. to cefazolin, CAZ, cefepime, and doripenem based on morphology changes. Within 90 min at MICs, they showed $\beta$-lactams induced cell shape changes in susceptible strains such as elongation, cell swelling or cell lysis; however, cell morphology remained unchanged for resistant strains [23]. Here, at MICs and at concentrations that would be used to interpret AMC and CAZ susceptibility by conventional BMD, both resistant and susceptible $B$. pseudomallei strains demonstrated morphology changes early on. However, filamentation could not be used as rapid indicator of susceptibility. Evidence of elongation was observed for resistant strains, and cell lysis could not determine an MIC since filamentation was observed for several strains at these concentrations. Even in IPM, the time to cell lysis was variable between strains and did not always occur rapidly.

Otero et al. [22] also developed a rapid (75 min) assay to detect antimicrobial resistance of Gram-negative spp. (A. baumannii, K. pneumonia, and $P$. aeruginosa) based on cell elongation in CAZ and established concentration ranges in which susceptible strains increased in length, but resistant strains did not. These drug ranges were several dilutions lower than the CLSI breakpoints used for conventional BMD susceptibility testing for these pathogens. While we performed $\beta$-lactam AST using concentrations below, equal to, and above MICs, including at those that could be used to interpret susceptibility by BMD, morphological differences between susceptible and resistant B. pseudomallei strains were not assessed at lower concentrations in this study. Choi et al. [21], developed a rapid AST based on single-cell morphological analysis and reported that some resistant Gram-negative bacteria, such as $P$. aeruginosa, can both deform in shape and still divide in the presence of IPM and piperacillin; this observation is accounted for in their assay. Recent development of a microplate-based surface area 
assay for rapid phenotypic AST also allows for more accurate measurements of replication when bacteria filament or swell [45].

Due to the complex and dynamic nature of bacterial morphology, developing a rapid $\beta$-lactam AST based on cell shape alone proves complicated. We demonstrate that B. pseudomallei morphology is dependent on strain, $\beta$-lactam exposure time and antibiotic concentration. Quantitative morphological data represents a snapshot in time of continuously fluctuating bacterial cells. Observations of morphological heterogeneity of certain cell populations in the presence of $\beta$-lactams highlight the need for data from additional bacteria to accurately interpret the response. We also showed, in sub-inhibitory concentrations, resistant strains undergo filamentation during early growth phase, similar to susceptible strains. Despite the limited number of resistant B. pseudomallei strains available in our collection to evaluate and the biosafety and biosecurity challenges associated with working with this pathogen, trends in morphology could be used to inform both bacterial response to $\beta$-lactams and antibiotic mechanisms of action. Identification of putative PBPs in the B. pseudomallei genome reveals the possible targets for $\beta$-lactams. Future studies that assess the cell morphology of additional B. pseudomallei strains as well as characterizing PBPs and binding affinities of $\beta$-lactams may build on these findings. A greater understanding of $\beta$-lactam-induced cell morphology changes could contribute to more meaningful clinical decisions for melioidosis patients or provide critical strain-specific information during an outbreak or public health emergency.

\section{Conclusions}

Using optical microscopy, we describe the morphology dynamics of B. pseudomallei strains with distinct AST profiles, exposed to clinically relevant $\beta$-lactam antibiotics. Ten genes encoding putative PBPs in the B. pseudomallei genome were identified and represent potential targets for $\beta$-lactams. Both resistant and susceptible strains exhibited filamentation during early exposure to AMC and CAZ at concentrations used to interpret susceptibility (based on CLSI guidelines). While developing a rapid $\beta$-lactam AST based on cell-shape alone requires more extensive analyses, growth attributes of B. pseudomallei reveal information about antibiotic response and antibacterial mechanisms of action.

\section{Methods}

\section{Bacterial strains, growth conditions and biosafety} procedures

Seven B. pseudomallei strains from our CDC collection were selected for this study based on unique antimicrobial susceptibility profiles and variable MICs including one multidrug-resistant (MDR) and two AMC-resistant (AMC-R) strains (Tables 1, 2, and 3). From glycerol stocks maintained at $-70^{\circ} \mathrm{C}$, bacterial strains were cultured overnight on trypticase soy agar II with 5\% sheep's blood (SBA) (Fisher Scientific, Pittsburg, PA) at $35^{\circ} \mathrm{C}$ in ambient air for testing. All work with $B$. pseudomallei was completed inside a class II type A2 biological safety cabinet located in a BSL-3 laboratory registered with the U.S. Federal Select Agent Program and is subject to select agent regulations (42-CFR-Part-73). Procedures were performed by trained personnel wearing a powered air-purifying respirator and protective laboratory clothing [46].

\section{Antimicrobials and susceptibility testing by BMD}

Antimicrobial susceptibility profiles for each strain are listed in Table 1. Minimal inhibitory concentrations (MIC) were first determined by conventional BMD testing following CLSI guidelines for medium, inoculum, and incubation temperature [47]. BMD susceptibility testing panels were prepared with Cation-Adjusted Mueller Hinton Broth (CAMHB) in house. $\beta$-lactam antibiotics selected for this study were amoxicillinclavulanic acid (AMC) (Toku-E, Bellingham, WA and USP, Frederick, MD), ceftazidime (CAZ) (Sigma Aldrich, St. Louis, MO) and imipenem (IPM) (Toku-E, Bellingham, WA). Two-fold antibiotic concentrations were tested ranging from $0.06 / 0.03-128 / 64 \mu \mathrm{g} / \mathrm{ml}$ AMC, 0.06-128 $\mu \mathrm{g} / \mathrm{ml} \mathrm{CAZ,} \mathrm{and} \mathrm{0.03-64} \mathrm{\mu g/ml} \mathrm{IPM.} \mathrm{B.} \mathrm{pseu-}$ domallei strains were classified as resistant $(\mathrm{R})$, intermediate (I), or susceptible (S) based on interpretive criteria outlined by CLSI [47]. MICs were recorded after 16 to $20 \mathrm{~h}$ of incubation at $35^{\circ} \mathrm{C}$ ambient air, with the exception of MSHR1655 (43 h). Incubation was extended due to insufficient growth in the control well of the BMD panel.

\section{Susceptibility testing by optical screening}

An optical screening instrument, the oCelloScope (BioSense Solutions ApS, Farum, Denmark), was used for rapid $\beta$-lactam AST of B. pseudomallei strains. As previously described in McLaughlin et al. [20], 96-well Sensititre panels (Trek Diagnostics, ThermoFisher Scientific) containing desiccated AMC, CAZ and IPM were inoculated with $B$. pseudomallei cell suspensions in CAMHB with $\mathrm{N}$-tris (hydroxymethyl) methyl-2aminoethanesulfonic acid (TES) (Remel Inc., Lenexa, KS). From overnight SBA culture growth, inocula were prepared by making a cell suspension in CAMHB to a turbidity equivalent to $0.5 \mathrm{McF}$ arland standard followed by a 1:50 dilution in CAMHB. Antibiotic concentrations evaluated by optical screening-based susceptibility testing were $2 / 1-64 / 32 \mu \mathrm{g} / \mathrm{ml} \mathrm{AMC,} 1-128 \mu \mathrm{g} / \mathrm{ml} \mathrm{CAZ}$, and $0.12-32 \mu \mathrm{g} / \mathrm{ml}$ IPM. For drug concentrations tested 
below the Sensititre panel range, 1:2 dilutions of the desiccated antibiotic were made using the inocula as the diluent. Cell suspensions $(90 \mu \mathrm{l})$ were transferred to a 96-well flat bottom plate, sealed with a breathable film cover (Breathe-Easy Sealing Membranes, Sigma Aldrich, St. Louis, MO) and monitored over time by optical screening at $35^{\circ} \mathrm{C}$ in ambient air. Instrument-derived growth values were recorded every $20 \mathrm{~min}$ for 18 to 24 h. For each strain, susceptibility testing was performed with three technical replicates in two biological experiments.

\section{Growth kinetics and data analysis}

Automated growth kinetic experiments were performed using the Segmentation and Extraction Surface Area (SESA) algorithm of the oCelloScope-specific software, UniExplorer (v. 5.0.3). Using this algorithm, bacteria were identified in a scan area $(405 \mu \mathrm{m} \times 1408 \mu \mathrm{m})$ based on contrast against the background, and growth values were calculated by summarizing bacterial surface area. Growth kinetic graphs represent the average growth values $(n=3) \pm$ standard deviations (SD), where indicated, from scan areas in three individual wells during one representative experiment. Statistical analysis of growth data defined the time $(\mathrm{h})$ required to determine antimicrobial susceptibility. The statistical significance, with a confidence level of $95 \%$ ( $p$-value $<0.05$ ), between a susceptible strain grown in media with and without $\beta$ lactam antibiotics over time was calculated using a twotailed $\mathrm{t}$-test. The minimum incubation times required for $\beta$-lactam AST are reported as the average \pm SD from duplicate biological experiments $(n=3)$. Cell lysis was observed by video imaging and the time (in h) was recorded when growth values began to decrease continuously over time. Cell lysis time is represented as the mean time $(\mathrm{n}=3) \pm \mathrm{SD}$.

\section{Cell morphology imaging by optical screening}

Real-time imaging of $B$. pseudomallei broth cultures in microtiter panel wells was performed simultaneously with $\beta$-lactam AST using the oCelloScope instrument. Strains with distinctive MIC values by BMD were selected for morphological analysis in the presence of each drug; AMC (Bp1651, MSHR1655, 724644, 6788, and 1026b), CAZ (Bp1651, MSHR1655, 724644, and 1026b), and IPM (Bp1651, MSHR1655, 724644, 1026b, 1631 and 6296). Images captured in CAMHB media without drug and in media containing either AMC, CAZ, or IPM at final concentrations below, at and above MICs during exponential and stationary phase growth. From each well containing $90 \mu \mathrm{l}$ of culture, 10 images were taken from a tilted image plane to produce a $\mathrm{z}$-stack image and videos were composed of z-stack images acquired over time. A 'best focused' image of 10 images was automatically selected through the UniExplorer Software and is depicted in figures. Times (h) in which strains were exposed to antibiotics are indicated in each figure legend.

\section{Analysis of bacterial cell length}

The Segmentation task of UniExplorer was used to analyze individual cells from optical screen images of $B$. pseudomallei. Unless otherwise indicated, cell length was measured after $4 \mathrm{~h}$ utilizing the 'thinned length' object feature. For each strain analyzed, 95 to 100 cells were measured in media with and without the presence of antibiotic and the distribution of cell lengths were graphically represented by histogram or dot plot. The median cell length value is the midpoint of this distribution.

\section{Identification of penicillin binding protein homologs}

Putative PBPs in B. pseudomallei 1026b were identified using the search feature of the UniProtKB database (https://www.uniprot.org/uniprot/), an online resource for protein sequence and annotation data. The Pfam database (http://pfam.xfam.org/) was utilized to predict conserved protein domains. Genes encoding putative PBPs in the 1026b genome (NCBI accession \# CP002833, CP002834) were used as queries to identify corresponding homologs in Bp1651 (NCBI accession \# CP012041, CP012042), MSHR1655 (NCBI accession \# CP008779, CP008780), and Bp6296 (NCBI accession \# CP018393, CP018394), in which completed assembled genomes are publicly available on NCBI. The nearest PBP protein homologs in $P$. aeruginosa PAO1 (NCBI accession \# NP 253108) were found using NCBI Protein BLAST and percent identities were based on amino acid sequence alignments.

\section{Supplementary information}

Supplementary information accompanies this paper at https://doi.org/10. 1186/s12866-020-01865-W.

Additional file 1: Figure S1. Growth kinetics of $B$. pseudomallei strains evaluated over $18 \mathrm{~h}$ in the presence and absence of $\boldsymbol{\beta}$ lactams. Bp1651 exposed to AMC (A) and IPM (B), MSHR1655 exposed to CAZ (C) and 724644 exposed to IPM (D). Drug concentrations ( $\mu \mathrm{g} / \mathrm{ml})$ corresponding to the CLSI breakpoint for susceptibility (green dots) and MICs (blue dots). Graphs represent the average \pm standard deviation from triplicate samples. Amoxicillin-clavulanic acid (AMC), ceftazidime (CAZ), and imipenem (IPM)

Additional file 2: Figure S2. Cell morphology of B. pseudomallei 6788 in the presence and absence of AMC $(\mu \mathrm{g} / \mathrm{ml})$. Optical screen images were captured after $6 \mathrm{~h}$. Amoxicillin-clavulanic acid (AMC), CLSI breakpoints for susceptibility (green dotted line), MIC (blue line).

Additional file 3.

Additional file 4.

Additional file 5.

Additional file 6.

Additional file 7.

Additional file 8. 


\section{Abbreviations}

AST: Antimicrobial susceptibility test; BMD: Broth microdilution; CLSI: Clinical and Laboratory Standards Institute; IPM: Imipenem; CAZ: Ceftazidime; AMC: Amoxicillin-clavulanic acid; MEM: Meropenem; MDR: Multidrugresistant; R: Resistant; I: Intermediate; S: Susceptible; SBA: Trypticase Soy Agar II with 5\% sheep blood; CAMHB: Cation-adjusted Mueller Hinton broth; MIC: Minimal inhibitory concentrations; TES: N-tris (hydroxymethyl) methyl-2aminoethanesulfonic acid; SESA: Segmentation and Extraction Surface Area; SD: Standard deviation; PBPs: Penicillin-binding proteins

\section{Acknowledgements}

We thank Jay E. Gee in the Division of High-Consequence Pathogens and Pathology at the Centers for Disease Control and Prevention for his review of this manuscript. We also acknowledge the team at BioSense Solutions ApS (Farum, Denmark) for their technical support.

\section{Disclaimer}

The findings and conclusions in this report are those of the authors and do not necessarily represent the official position of the Centers for Disease Control and Prevention. Use of trade names is for identification only and does not imply endorsement by the Centers for Disease Control and Prevention.

\section{Authors' contributions}

Design and conception of experiments: HM, DS. Execution of experiments: HM and JB. Data analysis: HM. Drafting the manuscript: HM, DS. Corrections and approval of the final manuscript: HM, JB and DS. All authors read and approved the final manuscript.

\section{Funding}

This work was supported by an interagency agreement HDTRA1213740 with the Department of Defense (DoD), Defense Threat Reduction Agency (DTRA) and Joint Science and Technology Office (JSTO). The funding bodies did not play a role in the design of the study, in the collection, analysis and interpretation of data, or in writing the manuscript.

\section{Availability of data and materials}

Datasets used and analyzed for this study are available from the corresponding author upon request.

\section{Ethics approval and consent to participate} Not Applicable.

\section{Consent for publication}

Not Applicable.

\section{Competing interests}

None.

Received: 16 January 2020 Accepted: 18 June 2020

Published online: 16 July 2020

\section{References}

1. World Health Organization. Antimicrobial resistance: global report on surveillance. Geneva: World Health Organization; 2014.

2. Centers for Disease Control and Prevention. Antibiotic resistance threats in the United States. Atlanta: U.S. Department of Health and Human Services, Centers for Disease Control and Prevention; 2019.

3. Perez KK, Olsen RJ, Musick WL, Cernoch PL, Davis JR, Peterson LE, Musser JM. Integrating rapid diagnostics and antimicrobial stewardship improves outcomes in patients with antibiotic-resistant gram-negative bacteremia. J Inf Secur. 2014;69:216-25.

4. Spellberg B, Guidos R, Gilbert D, Bradley J, Boucher HW, Scheld WM, Bartlett $J G$, Edwards J Jr. Infectious diseases Society of a: the epidemic of antibioticresistant infections: a call to action for the medical community from the Infectious Diseases Society of America. Clin Infect Dis. 2008;46:155-64.

5. Silver LL, Bush K. Antibiotics and antibiotic resistance. New York: Cold Spring Harbor Press; 2015

6. Shaikh S, Fatima J, Shakil S, SMD R, Kamal MA. Antibiotic resistance and extended spectrum beta-lactamases: Types, epidemiology and treatment. Saudi J Biol Sci. 2015;22:90-101.
7. Cheng AC, Currie BJ. Melioidosis: epidemiology, pathophysiology, and management. Clin Microbiol Rev. 2005;18:383-416.

8. Limmathurotsakul D, Golding N, Dance DA, Messina JP, Pigott DM, Moyes CL, Rolim DB, Bertherat E, Day NP, Peacock SJ. Predicted global distribution of Burkholderia pseudomallei and burden of melioidosis. Nat Microbiol. 2016;1:15008

9. Lipsitz R, Garges S, Aurigemma R, Baccam P, Blaney DD, Cheng AC, Currie BJ, Dance D, Gee JE, Larsen J, et al. Workshop on treatment of and postexposure prophylaxis for Burkholderia pseudomallei and B. mallei Infection, 2010. Emerg Infect Dis. 2012;18:e2.

10. Wiersinga WJ, Virk HS, Torres AG, Currie BJ, Peacock SJ, Dance DA, Limmathurotsakul D. Melioidosis. J Nature reviews Disease primers. 2018;4 17107.

11. Schweizer HP. Mechanisms of antibiotic resistance in Burkholderia pseudomallei: implications for treatment of melioidosis. Future Microbiol. 2012;7:1389-99.

12. Suputtamongkol $Y$, Rajchanuwong A, Chaowagul W, Dance DA, Smith MD, Wuthiekanun V, Walsh AL, Pukrittayakamee S, White NJ. Ceftazidime vs. amoxicillin/clavulanate in the treatment of severe melioidosis. Clin Infect Dis. 1994;19:846-53.

13. Sarovich DS, Price EP, Limmathurotsakul D, Cook JM, Von Schulze AT, Wolken SR, Keim P, Peacock SJ, Pearson T. Development of ceftazidime resistance in an acute Burkholderia pseudomallei infection. Infect Drug Resist. 2012;5:129-32.

14. Bugrysheva JV, Sue D, Gee JE, Elrod MG, Hoffmaster AR, Randall LB, Chirakul S, Tuanyok A, Schweizer HP, Weigel LM. Antibiotic resistance markers in Burkholderia pseudomallei strain Bp1651 identified by genome sequence analysis. Antimicrob Agents Chemother. 2017;61(6):e00010-17.

15. Rholl DA, Papp-Wallace KM, Tomaras AP, Vasil ML, Bonomo RA, Schweizer HP. Molecular investigations of PenA-mediated beta-lactam resistance in Burkholderia pseudomallei. Front Microbiol. 2011;2:139.

16. Sarovich DS, Price EP, Von Schulze AT, Cook JM, Mayo M, Watson LM, Richardson L, Seymour ML, Tuanyok A, Engelthaler DM, et al. Characterization of ceftazidime resistance mechanisms in clinical isolates of Burkholderia pseudomallei from Australia. PLoS One. 2012;7:e30789.

17. Chirakul S, Somprasong N, Norris MH, Wuthiekanun V, Chantratita N, Tuanyok A, Schweizer HP. Burkholderia pseudomallei acquired ceftazidime resistance due to gene duplication and amplification. Int J Antimicrob Agents. 2019;53:582-8

18. Chantratita N, Rholl DA, Sim B, Wuthiekanun V, Limmathurotsakul D, Amornchai $\mathrm{P}$, Thanwisai A, Chua HH, Ooi WF, Holden MT, et al. Antimicrobial resistance to ceftazidime involving loss of penicillin-binding protein 3 in Burkholderia pseudomallei. Proc Natl Acad Sci U S A. 2011;108:17165-70.

19. Gould IM, MacKenzie FM. The response of Enterobacteriaceae to betalactam antibiotics--'round forms, filaments and the root of all evil'. J Antimicrob Chemother. 1997:40:495-9.

20. McLaughlin HP, Sue D. Rapid antimicrobial susceptibility testing and betalactam-induced cell morphology changes of gram-negative biological threat pathogens by optical screening. BMC Microbiol. 2018;18:218.

21. Choi J, Yoo J, Lee M, Kim EG, Lee JS, Lee S, Joo S, Song SH, Kim EC, Lee JC, et al. A rapid antimicrobial susceptibility test based on single-cell morphological analysis. Sci Transl Med. 2014;6:267ra174.

22. Otero F, Santiso R, Tamayo M, Fernandez JL, Bou G, Lepe JA, McConnell MJ Gosalvez J, Cisneros JM. Rapid detection of antibiotic resistance in gramnegative Bacteria through assessment of changes in cellular morphology. Microb Drug Resist. 2017;23:157-62.

23. Su IH, Ko WC, Shih $\mathrm{CH}$, Yeh FH, Sun YN, Chen JC, Chen PL, Chang HC. Dielectrophoresis system for testing antimicrobial susceptibility of gramnegative Bacteria to beta-lactam antibiotics. Anal Chem. 2017;89:4635-41.

24. Buijs J, Dofferhoff AS, Mouton JW, Wagenvoort JH, van der Meer JW. Concentration-dependency of beta-lactam-induced filament formation in gram-negative bacteria. Clin Microbiol Infect. 2008;14:344-9.

25. Curtis NA, Orr D, Ross GW, Boulton MG. Affinities of penicillins and cephalosporins for the penicillin-binding proteins of Escherichia coli K-12 and their antibacterial activity. Antimicrob Agents Chemother. 1979;16:533-9.

26. Cushnie TT, O'Driscoll NH, Lamb AJ. Morphological and ultrastructural changes in bacterial cells as an indicator of antibacterial mechanism of action. Cell Mol Life Sci. 2016;73:4471-92.

27. Noguchi H, Matsuhashi M, Mitsuhashi S. Comparative studies of penicillinbinding proteins in Pseudomonas aeruginosa and Escherichia coli. Eur Biochem. 1979;100:41-9. 
28. Dalhoff A, Nasu T, Okamoto K. Target affinities of faropenem to and its impact on the morphology of gram-positive and gram-negative bacteria. Chemotherapy. 2003;49:172-83.

29. Waxman DJ, Strominger JL. Penicillin-binding proteins and the mechanism of action of beta-lactam antibiotics. Annu Rev Biochem. 1983;52:825-69.

30. Elliott TS, Greenwood D. The response of Pseudomonas aeruginosa to azlocillin, ticarcillin and cefsulodin. J Med Microbiol. 1983;16:351-62.

31. Dofferhoff AS, Buys J. The influence of antibiotic-induced filament formation on the release of endotoxin from Gram-negative bacteria. J Endotoxin Res. 1996;3:187-94

32. Chen K, Sun GW, Chua KL, Gan YH. Modified virulence of antibiotic-induced Burkholderia pseudomallei filaments. Antimicrob Agents Chemother. 2005; 49:1002-9.

33. Lorian V, Sabath LD. Penicillins and cephalosporins: differences in morphologic effects on Proteus mirabilis. J Infect Dis. 1972;125:560-4.

34. Fung-Tomc JC, Huczko E, Banville J, Menard M, Kolek B, Gradelski E, Kessler RE, Bonner DP. Structure-activity relationships of carbapenems that determine their dependence on porin protein D2 for activity against Pseudomonas aeruginosa. Antimicrob Agents Chemother. 1995; 39:394-9.

35. Bernabeu-Wittel M, Garcia-Curiel A, Pichardo C, Pachon-lbanez ME, JimenezMejias ME, Pachon J. Morphological changes induced by imipenem and meropenem at sub-inhibitory concentrations in Acinetobacter baumannii. Clin Microbiol Infect. 2004;10:931-4.

36. Peach KC, Bray WM, Winslow D, Linington PF, Linington RG. Mechanism of action-based classification of antibiotics using high-content bacterial image analysis. Mol BioSyst. 2013;9:1837-48.

37. Fitz-James $P$, Hancock R. The initial structural lesion of penicillin action in bacillus megaterium. J Cell Biol. 1965;26:657-67.

38. Satta G, Cornaglia G, Mazzariol A, Golini G, Valisena S, Fontana R. Target for bacteriostatic and bactericidal activities of beta-lactam antibiotics against Escherichia coli resides in different penicillin-binding proteins. Antimicrob Agents Chemother. 1995;39:812-8.

39. Cross T, Ransegnola B, Shin J-H, Weaver A, Fauntleroy K, VanNieuwenhze M, Westblade LF, Dörr T. Spheroplast-mediated carbapenem tolerance in Gram-negative pathogens. Antimicrob Agents Chemother. 2019;63:578559.

40. Roberts D, Higgs E, Rutman A, Cole P. Isolation of spheroplastic forms of Haemophilus influenzae from sputum in conventionally treated chronic bronchial sepsis using selective medium supplemented with N-acetyl-Dglucosamine: possible reservoir for re-emergence of infection. Br Med J (Clin Res Ed). 1984;289:1409-12.

41. Bergeron MG, Lavoie GY. Tolerance of Haemophilus influenzae to betalactam antibiotics. Antimicrob Agents Chemother. 1985;28:320-5.

42. Khosravi Y, Vellasamy KM, Mariappan V, Ng S-L, Vadivelu J. Antimicrobial susceptibility and genetic characterisation of Burkholderia pseudomallei isolated from Malaysian patients. Sci World J. 2014;2014:132971.

43. Dance D. Treatment and prophylaxis of melioidosis. Int J Antimicrob Agents. 2014;43:310-8.

44. Mulroney KT, Hall JM, Huang X, Turnbull E, Bzdyl NM, Chakera A, Naseer U, Corea EM, Ellington MJ, Hopkins KL, et al. Rapid susceptibility profiling of carbapenem-resistant Klebsiella pneumoniae. Sci Rep. 2017;7:1903.

45. Flentie K, Spears BR, Chen F, Purmort NB, DaPonte K, Viveiros E, Phelan N, Krebill C, Flyer AN, Hooper DC, et al. Microplate-based surface area assay for rapid phenotypic antibiotic susceptibility testing. Sci Rep. 2019;9:237.

46. Chosewood LC, Wilson DE. Centers for Disease Control and Prevention (U.S.), National Institutes of Health (U.S.): Biosafety in microbiological and biomedical laboratories. 5th edn. Washington, D.C.: U.S. Dept. of Health and Human Services, Public Health Service, Centers for Disease Control and Prevention, National Institutes of Health; 2009

47. CLSI. Methods for antimicrobial diluiton and disc susceptibility testing of infrequently isolated or fastidious bacteria, 3rd ed. M45. Wayne: CLSI; 2016

\section{Publisher's Note}

Springer Nature remains neutral with regard to jurisdictional claims in published maps and institutional affiliations.

\section{Ready to submit your research? Choose BMC and benefit from:}

- fast, convenient online submission

- thorough peer review by experienced researchers in your field

- rapid publication on acceptance

- support for research data, including large and complex data types

- gold Open Access which fosters wider collaboration and increased citations

- maximum visibility for your research: over $100 \mathrm{M}$ website views per year

At BMC, research is always in progress.

Learn more biomedcentral.com/submissions 